\title{
Determinants of polypharmacy and compliance with GOLD guidelines in patients with chronic obstructive pulmonary disease
}

This article was published in the following Dove Press journal:

International Journal of COPD

23 September 2011

Number of times this article has been viewed

\author{
Frits ME Franssen' \\ Martijn A Spruit \\ Emiel FM Wouters ${ }^{1,2}$ \\ 'Program Development Center, \\ CIRO+, Center of Expertise for \\ Chronic Organ Failure, Horn, \\ The Netherlands; ' ${ }^{2}$ Department of \\ Respiratory Medicine, Maastricht \\ University Medical Center, Maastricht, \\ The Netherlands
}

Correspondence: Frits ME Franssen Center of Expertise for Chronic Organ Failure, PO Box 4080, 6080 AB Haelen, The Netherlands

Tel +3 I 475587600

Fax +3। 475587592

Email fritsfranssen@ciro-horn.nl
Background: Polypharmacy of respiratory medications is commonly observed in patients with chronic obstructive pulmonary disease (COPD). The aims of this study were to investigate determinants of polypharmacy and to study the consistency of actual respiratory drug use with current Global Initiative for Chronic Obstructive Lung Disease (GOLD) guidelines in pulmonary rehabilitation candidates with COPD.

Methods: Data were extracted from the records of all patients with a diagnosis of COPD referred for pulmonary rehabilitation to CIRO+ between 2005 and 2009. Use of respiratory medications, self-reported COPD exacerbations, lung function, blood gases, exercise capacity, Medical Research Council (MRC) dyspnea grade, and St George's Respiratory Questionnaire (SGRQ) were recorded as part of assessment of health status.

Results: In total, 1859 COPD patients of mean age ( \pm standard deviation) $64.3 \pm 9.7$ years and with a forced expiratory volume in one second $\left(\mathrm{FEV}_{1}\right)$ of $44.7 \% \pm 18.2 \%$ were included. On average, patients used $3.5 \pm 1.5$ respiratory medications; this number increased with increasing GOLD stage, MRC score, and SGRQ scores. FEV (\% predicted), SGRQ, and number of recent exacerbations were independent determinants of polypharmacy. Use of long-acting bronchodilators and inhaled corticosteroids was substantial and comparable in all GOLD stages. Use of corticosteroids was not restricted to patients with frequent exacerbations.

Conclusion: Polypharmacy of respiratory medications is common in COPD patients with persistent symptoms. In addition to severity of disease, health status is an independent predictor of polypharmacy. Actual drug use in COPD patients referred for pulmonary rehabilitation is partially inconsistent with current GOLD guidelines.

Keywords: chronic obstructive pulmonary disease, management, pharmacotherapy, polypharmacy, pulmonary rehabilitation, respiratory drug use

\section{Introduction}

Chronic obstructive pulmonary disease (COPD) is a major cause of morbidity and mortality worldwide and results in substantial social and economic burden, including both direct and indirect costs. ${ }^{1}$ It is projected that the burden of this disease will increase in the next decade and that COPD will become the third leading cause of death by $2020 .^{2}$

Although the chronic airflow limitation characteristic of the disease cannot be cured, both pharmacologic and nonpharmacologic treatment is available for patients with COPD. Effective pharmacologic management of the disease results in relief of symptoms, ${ }^{3,4}$ improvement in lung function, ${ }^{3,5,6}$ health status, ${ }^{5,6}$ exercise tolerance, ${ }^{7,8}$ and reduction in frequency ${ }^{5,6}$ and severity of exacerbations. ${ }^{9}$ Until now, modification 
of disease progression ${ }^{4,5}$ and mortality ${ }^{6,10}$ by pharmacotherapy has not been convincingly demonstrated, although several recent trials suggest a beneficial effect of pharmacologic treatment on the rate of decline in lung function. ${ }^{11-13}$

In order to provide a benchmark for evidence-based pharmacologic therapy and facilitate the development of cost-effective care, the Global Initiative for Chronic Obstructive Lung Disease (GOLD) consensus statement ${ }^{14}$ provides recommendations for pharmacotherapy in COPD. In clinically stable patients, the introduction of respiratory medications according to these guidelines follows a step-up principle based on the level of disease severity assessed by postbronchodilator forced expiratory volume in the first second $\left(\mathrm{FEV}_{1}\right)$, the presence of clinical symptoms, and the occurrence of acute exacerbations. Recommended initial pharmacotherapy consists of short-acting bronchodilators, followed by the introduction of long-acting bronchodilators in moderately severe patients with persisting dyspnea and the addition of inhaled corticosteroids in patients with severe or very severe disease and recurring exacerbations. Xanthine derivates may provide additional reduction of symptoms cumulative to long-acting bronchodilators. According to current evidence, chronic use of systemic corticosteroids must be avoided. ${ }^{14}$ Finally, antioxidant agents have no additional benefit in the pharmacologic treatment of stable COPD. ${ }^{14}$

To date, no studies have assessed whether the routine practice of respiratory physicians is consistent with these international guidelines for pharmacotherapy in COPD. In clinical practice, polypharmacy with respiratory drugs is commonly observed. This substantially contributes to direct medical costs in COPD. ${ }^{1}$ In addition, overuse of respiratory medications is an important risk factor for adverse effects. ${ }^{15}$ Furthermore, polypharmacy and prescription of multiple daily doses contribute to poor patient adherence in COPD, which is a significant concern. ${ }^{16}$ Although higher age, female gender, and the presence of multiple comorbidities are some of the factors correlated with polypharmacy in the elderly, ${ }^{17}$ determinants of polypharmacy with respiratory medications in COPD have not yet been investigated.

The primary aim of the present study was to explore factors related to polypharmacy with respiratory drugs, including age, gender, health status, and the occurrence of exacerbations in COPD patients with persistent symptoms referred for clinical assessment and pulmonary rehabilitation. Secondly, the consistency of prescriptions and actual use of respiratory drugs with the current GOLD guidelines for pharmacotherapy was investigated in a tertiary care setting.

\section{Methods}

\section{Subjects}

Data were extracted from the records of all patients admitted to CIRO+, Center of Expertise for Chronic Organ Failure in Horn, The Netherlands, for clinical evaluation and pulmonary rehabilitation between January 1, 2005 and December 31, 2009. Referral to the center is reserved to respiratory physicians. Only data from patients with a primary diagnosis of COPD confirmed by the referring respiratory physician were included in this study. Data from patients with alternative or additional respiratory conditions, including asthma or lung cancer, were excluded. In addition, spirometric data from patients had to fulfill the criteria of chronic airflow limitation, defined as postbronchodilator forced expiratory volume in one second $\left(\mathrm{FEV}_{1}\right)$ /forced vital capacity $<0.7 .{ }^{14}$ These retrospective analyses are Institutional Review Board exempt due to the use of deidentified, pre-existing data. Some of the patients were part of a previous paper on problematic activities in daily life. ${ }^{18}$

\section{Assessment of respiratory drug therapy and exacerbations}

During medical consultation at $\mathrm{CIRO}+$, all respiratory drugs prescribed by secondary care respiratory physicians were routinely recorded, and the actual use of these drugs was verified with the patients. Respiratory medications were stratified into six classes, ie, short-acting bronchodilators (short-acting $\beta_{2}$-agonists, short-acting anticholinergics, shortacting combined bronchodilators), long-acting bronchodilators (long-acting $\beta_{2}$-agonists alone or in combination with inhaled corticosteroids, and long-acting anticholinergics), inhaled corticosteroids (alone or in combination with longacting $\beta_{2}$-agonists), systemic corticosteroids, theophylline, and $\mathrm{N}$-acetylcysteine. The number of patient-reported COPD exacerbations in the 12 months prior to assessment was consistently annotated during medical history. If possible, exacerbations were verified in the written medical correspondence from the referring respiratory physician on application for pulmonary rehabilitation. Patients with three or more exacerbations in the last year were considered frequent exacerbators. ${ }^{19}$

\section{Clinical assessment}

In order to evaluate the integrated health status of referred patients, a comprehensive assessment was routinely performed at the CIRO+. ${ }^{20}$ Postbronchodilator $\mathrm{FEV}_{1}$ and forced vital capacity were calculated from the flow-volume curve using spirometry. Carbon monoxide transfer factor of the 
lung $\left(\mathrm{DL}_{\mathrm{CO}}\right)$ was determined using the single breath method. Lung function parameters were expressed as a percentage of reference values. ${ }^{21}$ Arterial oxygen tension and arterial carbon dioxide tension were analyzed using a blood gas analyzer. Based on lung function and blood gases, patients were stratified into GOLD stages for severity of COPD.${ }^{14}$ In addition to determination of body weight and height, body composition was assessed using single-frequency bioelectrical impedance assessment after overnight fasting. A COPD-specific regression equation was used to calculate fat-free mass. ${ }^{22}$ Functional exercise capacity was assessed by the six-minute walk test (performed twice ${ }^{23}$ ) and was expressed as percentage of predicted. ${ }^{24}$ Self-perceived dyspnea in relation to physical disability was measured by the Medical Research Council (MRC) dyspnea scale. ${ }^{25}$ The St George's Respiratory Questionnaire (SGRQ) was used to assess disease-specific health status, ${ }^{26}$ consisting of three domains (symptoms, activity and impact) and a total score. Scores range from 0 (optimal) to 100 points (worst).

\section{Statistics}

All statistics were performed using the Statistical Package for the Social Sciences (SPSS) version 17.0.0 (SPSS Inc, Chicago, IL). Results are expressed as the mean \pm standard deviation. The independent samples Student's $t$-test was used to investigate gender differences within the COPD group and differences between COPD patients with and without frequent exacerbations. SGRQ data were stratified into quartiles. Differences between COPD GOLD stages, MRC strata, and SGRQ quartiles were investigated by one-way analysis of variance, using Fisher's Least Significant Difference as a post hoc test. Pearson's correlation analysis was performed in order to study linear relationships between the number of respiratory medications and parameters of integrated health status. Stepwise linear regression analysis was done to identify independent determinants of the prescribed number of respiratory drugs. Differences in the proportion of patients using the various categories of respiratory medications and individual compounds between different GOLD stages and between patients with and without frequent exacerbations were assessed using Chi-square test. All $P$ values $<0.05$ were considered to be statistically significant.

\section{Results}

From January 1, 2005 until December 31, 2009, a total number of 2561 subjects was referred to CIRO+ for comprehensive assessment and pulmonary rehabilitation. COPD was the primary pulmonary diagnosis on referral by a secondary care respiratory physician in 1988 (78\%) of these subjects. One-hundred and twenty nine of the subjects were excluded from analyses because postbronchodilator $\mathrm{FEV}_{1} /$ forced vital capacity during assessment in $\mathrm{CIRO}+$ was $\geq 0.7$. The final analyses in this study included data from 1859 patients with mild to very severe COPD. Distribution of disease severity and other characteristics of these subjects are reported in Table 1. Forty-one percent of subjects were current smokers. On average, diffusion capacity was moderately impaired and subjects were normoxemic and normocapnic. Group values for body weight and fat-free mass were in the normal range. Overall, functional exercise capacity was moderately impaired, subjects experienced limitation of activity due to breathlessness during daily life, and had a severely impaired health status.

On average, COPD patients used $3.5 \pm 1.5$ respiratory medications. Variation in the number of respiratory drugs was wide (Figure 1A), with $5 \%$ of patients using no medication, while $22 \%$ of patients took five or more respiratory prescriptions per day. The number of respiratory medications was comparable between male and female patients with COPD (3.4 \pm 1.5 versus $3.5 \pm 1.5$, respectively, not significant). The number of respiratory drugs increased with advancement in GOLD stage (Figure 1B). Also, COPD patients in the

Table I Subject characteristics (mean \pm standard deviation)

\begin{tabular}{|c|c|}
\hline Patients, number & I 859 (58\% males) \\
\hline Age, years & $64.3 \pm 9.7$ \\
\hline Current smokers & $41 \%$ \\
\hline $\mathrm{FEV}_{1}$, liters & $1.18 \pm 0.53$ \\
\hline $\mathrm{FEV}_{1}, \%$ predicted & $44.7 \pm 18.2$ \\
\hline $\mathrm{FEV}_{1} / \mathrm{FVC}$ & $39.2 \pm 11.7$ \\
\hline \multicolumn{2}{|l|}{ COPD severity } \\
\hline GOLD I, number (\%) & $89(4.8)$ \\
\hline GOLD II, number (\%) & 557 (29.9) \\
\hline GOLD III, number (\%) & $582(3 \mid .3)$ \\
\hline GOLD IV, number (\%) & $631(33.9)$ \\
\hline $\mathrm{DL}_{\mathrm{co}}, \%$ predicted & $51.7 \pm 18.9$ \\
\hline $\mathrm{BMI}, \mathrm{kg} / \mathrm{m}^{2}$ & $25.2 \pm 5.2$ \\
\hline FFMI, $\mathrm{kg} / \mathrm{m}^{2}$ & $16.4 \pm 2.9$ \\
\hline $\mathrm{P}_{\mathrm{a}} \mathrm{O}_{2}, \mathrm{kPa}$ & $9.4 \pm 1.3$ \\
\hline $\mathrm{P}_{\mathrm{a}} \mathrm{CO}_{2}, \mathrm{kPa}$ & $5.4 \pm 1.4$ \\
\hline 6MWD & $416 \pm 129$ \\
\hline 6MWD, \% predicted & $67 \pm 18$ \\
\hline MRC & $3.6 \pm 1.2$ \\
\hline SGRQ, symptoms & $61 \pm 21$ \\
\hline SGRQ, activity & $71 \pm 19$ \\
\hline SGRQ, impact & $44 \pm 19$ \\
\hline SGRQ, total & $55 \pm 17$ \\
\hline
\end{tabular}

Abbreviations: $\mathrm{FEV}$, forced expiratory volume in one second; $\mathrm{FVC}$, forced vital capacity; $\mathrm{DL}_{\mathrm{co}}$, diffusing capacity for carbon monoxide; BMI, body mass index; FFMI, fat-free mass index; $\mathrm{P}_{\mathrm{a}} \mathrm{O}_{2}$, arterial oxygen tension; $\mathrm{P}_{\mathrm{a}} \mathrm{CO}_{2}$, arterial carbon dioxide tension; 6MWD, six-minute walk distance; MRC, Medical Research Council dyspnea score; SGRQ, St George's Respiratory Questionnaire. 

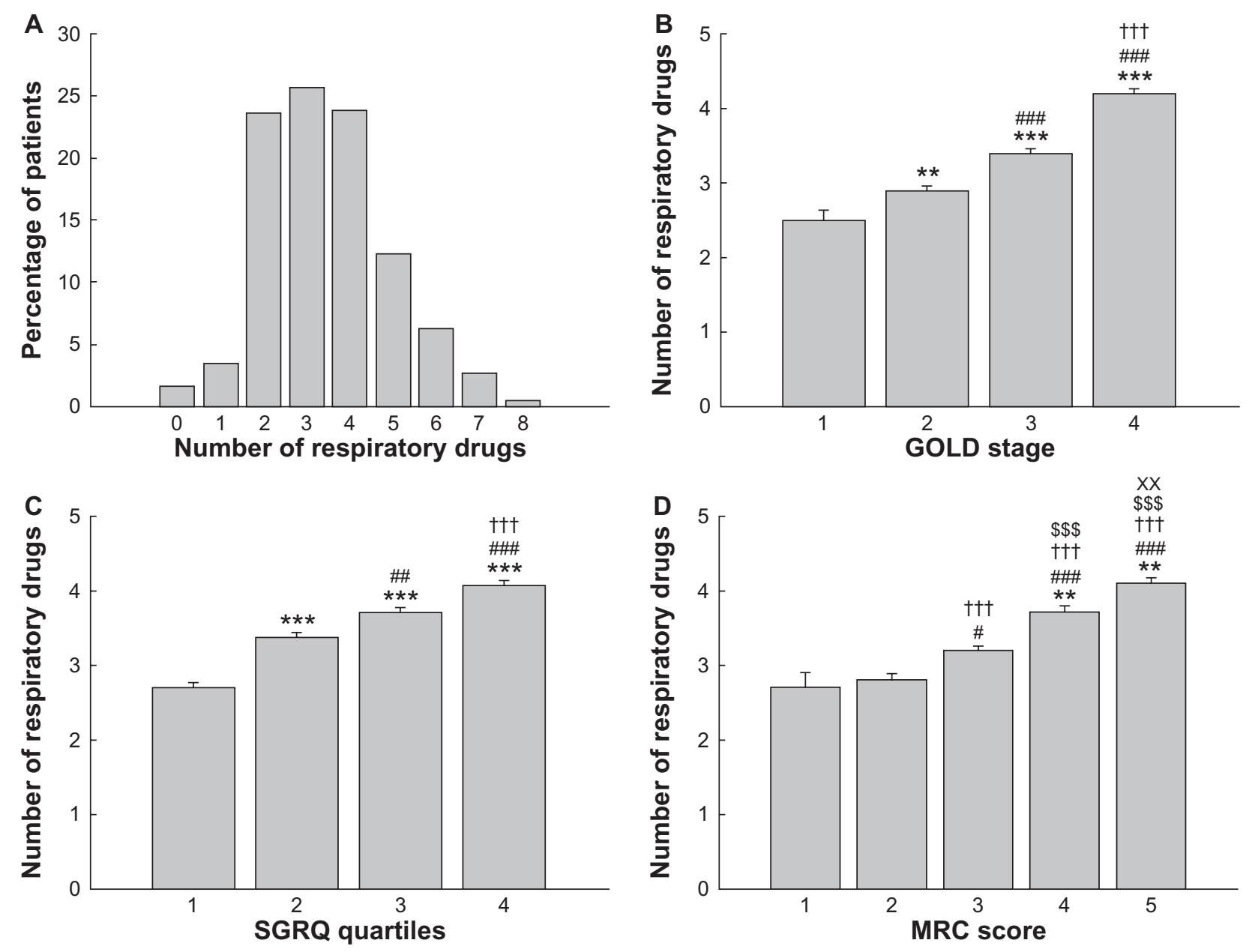

Figure I Number of respiratory medications in patients with COPD $(n=1859)$. (A) Variation in number of respiratory drugs in patient population. (B) Number of respiratory drugs in different GOLD stages. ***P $<0.00$ I, $* * P<0.0$ I versus GOLD I; $P<0.00$ I versus GOLD 2; $t+t P<0.00$ I versus GOLD 3. (C) Number of respiratory drugs

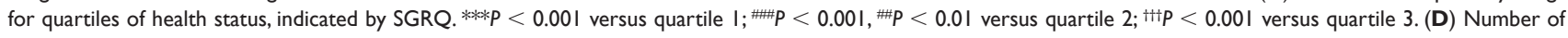
respiratory medications in relation to Medical Research Council (MRC) dyspnea score. ${ }^{* * P}<0.0 \mathrm{I}$ versus MRC 0 ; $P<0.00 \mathrm{I}$, $P P<0.05$ versus MRC I; ${ }^{\# t} P<0.00 \mathrm{I}$ versus MRC 2; $\$ \$ \$ P<0.001$ versus MRC 3; $\times x p<0.01$ versus MRC 4.

Abbreviations: COPD, chronic obstructive pulmonary disease; GOLD, Global Initiative for Chronic Obstructive Lung Disease; MRC, Medical Research Council; SGRQ, St George's Respiratory Questionnaire.

upper quartiles of total SGRQ score and those with highest (worst) MRC dyspnea grade used more respiratory drugs, compared with those having lower scores on these outcomes (Figure $1 \mathrm{C}$ and D).

In bivariate correlation analysis, $\mathrm{FEV}_{1}(\%$ predicted, $\mathrm{r}=-0.346, P<0.001), \mathrm{DL}_{\mathrm{CO}}(\mathrm{r}=-0.097, P<0.001)$, number of exacerbations in previous 12 months $(\mathrm{r}=0.314, P<0.001)$, six-minute walk test $(\mathrm{r}=-0.300, P<0.001)$, arterial oxygen tension $(-0.050, P<0.05)$, arterial carbon dioxide tension $(\mathrm{r}=0.058, P<0.05)$, MRC dyspnea grade $(\mathrm{r}=0.339$, $P<0.001)$, SGRQ symptom score $(\mathrm{r}=0.299, P<0.001)$, SGRQ activity score $(\mathrm{r}=0.325, P<0.001)$, SGRQ impact score $(\mathrm{r}=0.301, P<0.001)$, and SGRQ total score $(\mathrm{r}=0.345$, $P<0.001)$ all significantly correlated with the number of respiratory drugs of the patients, while correlations with age $(r=0.024)$, body mass index $(r=0.043)$ and fat-free mass index $(r=0.031)$ were absent. Since there were multiple bivariate correlations between these factors, significant parameters were entered in a stepwise regression model with the number of respiratory medications as the dependent variable (Table 2). In addition to $\mathrm{FEV}_{1}$ (\% predicted), SGRQ total score, number of exacerbations in the previous 12 months, six-minute walk test, arterial oxygen tension, arterial carbon dioxide tension, and $\mathrm{DL}_{\mathrm{CO}}$ individually contributed to the model, while MRC dyspnea grade was excluded. The proportion of variance explained by the model $\left(\mathrm{R}^{2}\right)$ was 0.22 .

The percentage of COPD patients using the various categories of respiratory medications for the total group and for the different GOLD stages is displayed in Table 3. In general, the three most commonly used respiratory drugs were combination products of long-acting $\beta_{2}$-agonists/ inhaled corticosteroids, long-acting anticholinergics, and 
Table 2 Results of stepwise regression analysis for the number of respiratory drugs in patients with COPD

\begin{tabular}{|c|c|c|c|c|c|}
\hline \multirow[t]{2}{*}{ Model } & \multicolumn{2}{|c|}{ Unstandardized coefficients } & \multirow{2}{*}{$\frac{\text { Standardized coefficients }}{\text { Beta }}$} & \multirow[t]{2}{*}{$\mathbf{t}$} & \multirow[t]{2}{*}{ Significance } \\
\hline & B & Standard error & & & \\
\hline (Constant) & 6.015 & 0.777 & & 7.742 & 0.000 \\
\hline SGRQ total & 0.15 & 0.003 & 0.183 & 4.535 & 0.000 \\
\hline $\mathrm{FEV}_{1}, \%$ pred & -0.18 & 0.003 & -0.233 & -5.484 & 0.000 \\
\hline Exacerbations, no & 0.095 & 0.020 & 0.170 & 4.663 & 0.000 \\
\hline 6MWD, meters & -0.002 & 0.000 & -0.139 & -3.467 & 0.001 \\
\hline $\mathrm{P}_{\mathrm{a}} \mathrm{CO}_{2}, \mathrm{kPa}$ & 0.320 & 0.087 & 0.149 & 3.653 & 0.000 \\
\hline $\mathrm{DL}_{\mathrm{co}}, \%$ pred & 0.009 & 0.003 & 0.124 & 3.166 & 0.002 \\
\hline $\mathrm{P}_{\mathrm{a}} \mathrm{O}_{2}, \mathrm{kPa}$ & -0.100 & 0.041 & -0.097 & -2.428 & 0.015 \\
\hline
\end{tabular}

Abbreviations: SGRQ, St George's Respiratory Questionnaire; $\mathrm{FEV}_{1}$, forced expiratory volume in one second; $6 \mathrm{MWD}$, six-minute walk distance; $\mathrm{P}_{\mathrm{a}} \mathrm{CO} \mathrm{F}_{2}$, arterial carbon dioxide tension; $\mathrm{DL}_{\mathrm{cO}}$, diffusing capacity for carbon monoxide; $\mathrm{P}_{\mathrm{a}} \mathrm{O}_{2}$, arterial oxygen tension.

$\mathrm{N}$-acetylcysteine. The use of short-acting bronchodilators significantly increased with each advance in GOLD stage (Figure 2), and this increase in use in parallel with disease severity was observed for all individual components (Table 3). The percentage of patients using long-acting bronchodilators (either as a single inhaler or as part of a combination inhaler) was comparable in all GOLD stages, except for significantly less frequent use in GOLD 4 compared with GOLD 3 patients (Figure 2), as a result of a lower percentage of patients using long-acting anticholinergics in very severe COPD (Table 3). On average, almost $90 \%$ of GOLD 1 patients were taking any prescription containing a long-acting bronchodilator.

While patients with mild COPD used significantly fewer inhaled corticosteroids than patients with severe or very severe disease, the proportion of patients using inhaled corticosteroids (either as a single inhaler or as part of a combination inhaler) was comparable in GOLD 2, GOLD

Table 3 Percentage of patients using various categories of COPD medications in the total group and in the different GOLD stages

\begin{tabular}{|c|c|c|c|c|c|}
\hline Medication & Total & GOLD I & GOLD 2 & GOLD 3 & GOLD 4 \\
\hline SABA & 33.4 & 24.7 & 25.7 & $36.9 * \ldots \#$ & $38.2^{* \ldots \#}$ \\
\hline SAAC & 16.3 & 5.6 & $12.9 *$ & $14.6^{*}$ & $22.2^{2 * * * \ldots \#, t \dagger}$ \\
\hline COMBI & 29.0 & 9.0 & $18.3^{*}$ & 24.6 **,\# & $45.3^{* * *, \ldots+\ldots, t+t}$ \\
\hline LABA & 23.7 & 16.9 & 19.2 & $25 . I^{\#}$ & $27.4^{* \ldots}$ \\
\hline LAAC & 64.2 & 62.9 & 70.3 & 67.9 & $55.5^{\ldots \ldots \#,+t \dagger t}$ \\
\hline ICS & 18.4 & 12.4 & 12.8 & $17.5^{\#}$ & $24.9 * *, \ldots \#,+\dagger$ \\
\hline LABA-ICS & 68.1 & 68.5 & 72.1 & 70.6 & $62.3^{\ldots+1+1+t \dagger}$ \\
\hline OCS & 21.5 & 9.0 & 10.6 & $16.2^{\# \#}$ & $37.7^{* * * \ldots \ldots+, t+t}$ \\
\hline THEO & 17.8 & 4.5 & 11.1 & $16.2^{* * \# \#}$ & $27.1^{* * *, \ldots l l, t+t \dagger}$ \\
\hline NAC & 43.1 & 27.0 & 30.6 & 39.0* & $60.1 * * * \ldots \ldots+, t+t$ \\
\hline
\end{tabular}

Notes: Significance of differences between COPD GOLD stages is indicated by: $* * * P<0.001$, **P $<0.01$, $* P<0.05$ versus GOLD I; \# $P<0.001$, \#P $<0.01$, ${ }^{\#} P<0.05$ versus GOLD 2; ${ }^{t+p} P<0.001,{ }^{t+p}<0.01,{ }^{t} P<0.05$ versus GOLD 3.

Abbreviations: SABA, short-acting $\beta_{2}$-agonists; SAAC, short-acting anticholinergics; COMBI, short-acting combination bronchodilators; LABA, long-acting $\beta_{2}$-agonists; LAAC, long-acting anticholinergics; ICS, inhaled corticosteroids; LABA-ICS, combination of long-acting $\beta_{2}$-agonists and inhaled corticosteroids; OCS, oral corticosteroids; THEO, oral theophylline; NAC, oral $\mathrm{N}$-acetylcysteine.
3, and GOLD 4 (Figure 2). As shown in Figure 2, 78\% of GOLD 1 patients and $84 \%$ of GOLD 2 patients used any prescription of inhaled corticosteroids. There was a gradual increase in the proportion of patients using oral corticosteroids, theophylline, and N-acetylcysteine from mild to very severe disease (Table 3), with GOLD 3 and GOLD 4 patients using these oral drugs significantly more frequently.

COPD patients with frequent exacerbations were characterized by younger age, more severe airflow obstruction, increased MRC dyspnea grade, elevated scores on all SGRQ domains, and impaired six-minute walk test compared with patients with less frequent exacerbations (Table 4). A higher proportion of patients with frequent exacerbations used any inhaled corticosteroid in comparison with patients without frequent exacerbations $(89.4 \%$ versus $83.7 \%, P<0.01)$, which was explained by a higher percentage of patients

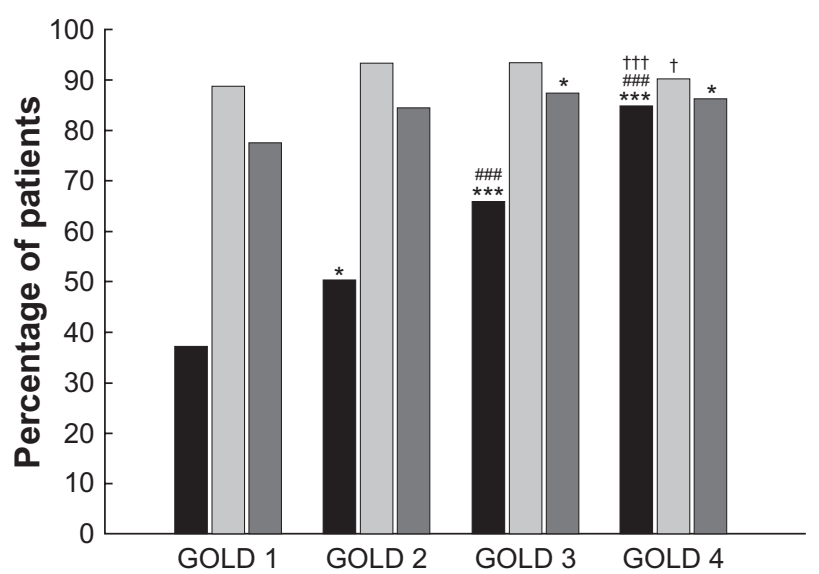

Figure 2 Proportion of COPD patients using various classes of inhaled respiratory medications, after stratification for GOLD stage. Black bars, short-acting bronchodilators; light gray bars, long-acting bronchodilators; dark gray bars, inhaled corticosteroids.

Notes: Significance of differences between GOLD COPD stages is indicated by: $* * * P<0.00$ I, $* P<0.05$ versus GOLD I; ${ }^{*} P<0.00$ I versus GOLD 2 ; ${ }^{t+t} P<0.00$ I, ${ }^{\dagger} P<0.05$ versus GOLD 3 .

Abbreviations: COPD, chronic obstructive pulmonary disease; GOLD, Global Initiative for Chronic Obstructive Lung Disease. 
Table 4 Differences in clinical characteristics between COPD patients with frequent exacerbations ( $\geq 3$ in the last year) and patients without frequent exacerbations (mean \pm standard deviation)

\begin{tabular}{lcc}
\hline Variables & $\begin{array}{l}\text { Frequent } \\
\text { exacerbations }\end{array}$ & $\begin{array}{l}\text { No frequent } \\
\text { exacerbations }\end{array}$ \\
\hline Age, years & $63.1 \pm 9.4$ & $64.8 \pm 9.7^{* *}$ \\
$\mathrm{FEV}_{1}$, liters & $1.05 \pm 0.48$ & $1.23 \pm 0.52^{* * *}$ \\
$\mathrm{FEV}_{1}, \%$ predicted & $40.7 \pm 17.2$ & $46.2 \pm 18.1^{* * *}$ \\
$\mathrm{FEV}_{1} / \mathrm{FVC}$ & $38.4 \pm 11.7$ & $39.5 \pm 11.6$ \\
$\mathrm{DL}_{\mathrm{CO}}, \%$ predicted & $50.1 \pm 20.1$ & $52.3 \pm 18.6$ \\
$\mathrm{BMI}, \mathrm{kg} / \mathrm{m}^{2}$ & $25.2 \pm 2.0$ & $25.1 \pm 5.2$ \\
$\mathrm{FFMI}, \mathrm{kg} / \mathrm{m}^{2}$ & $16.2 \pm 2.3$ & $16.4 \pm 2.3^{*}$ \\
$\mathrm{P}_{\mathrm{a}}, \mathrm{kPa}$ & $9.4 \pm 3.9$ & $9.5 \pm 3.2$ \\
$\mathrm{P}_{\mathrm{a}} \mathrm{CO}$, kPa & $5.4 \pm 0.7$ & $5.4 \pm 1.9$ \\
$6 \mathrm{MWD}$ & $390 \pm 127$ & $432 \pm 127^{* * *}$ \\
$6 \mathrm{MWD}, \%$ predicted & $63 \pm 17$ & $69 \pm 17^{* * *}$ \\
MRC & $3.9 \pm 1.1$ & $3.4 \pm 1.2^{* * *}$ \\
SGRQ, symptoms & $68 \pm 18$ & $57 \pm 21^{* * *}$ \\
SGRQ, activity & $78 \pm 16$ & $70 \pm 20^{* * *}$ \\
SGRQ, impact & $50 \pm 17$ & $42 \pm 19^{* * *}$ \\
SGRQ, total & $61 \pm 15$ & $53 \pm 17^{* * *}$ \\
\hline
\end{tabular}

Notes: Significance of differences between groups indicated by: $* * * P<0.001$; $* * P<0.0$ I; $* P<0.05$.

Abbreviations: $\mathrm{FEV}_{1}$, forced expiratory volume in one second; FVC, forced vital capacity; $\mathrm{DL}_{\mathrm{co}}$, diffusing capacity for carbon monoxide; BMI, body mass index; FFMI, fat-free mass index; $\mathrm{P}_{2} \mathrm{O}_{2}$, arterial oxygen tension; $\mathrm{P}_{2} \mathrm{CO}_{2}$, arterial carbon dioxide tension; 6MWD, six-minute walk distance; MRC, Medical Research Council dyspnea score; SGRQ, St George's Respiratory Questionnaire.

using single-inhaler corticosteroids $(24.1 \%$ versus $14.7 \%$, $P<0.001)$ while the proportion of patients taking corticosteroids as part of a combination product was comparable $(66.7 \%$ versus $69.5 \%)$ in both groups. The use of oral corticosteroids (33.5\% versus $14.1 \%, P<0.001)$, theophylline (24.6\% versus $14.3 \%, P<0.001), \mathrm{N}$-acetylcysteine $(53.9 \%$ versus $36.9 \%, P<0.001$ ), and short-acting bronchodilators (78.1\% versus $60.7 \%, P<0.001$ ) was significantly more prevalent in patients with frequent exacerbations compared with patients with no or less frequent exacerbations. The proportion of patients using long-acting bronchodilators was comparable between both groups, although long-acting anticholinergics were less frequently used in those with frequent exacerbations, compared to patients with no or less frequent exacerbations $(60.7 \%$ versus $66.3 \%, P<0.001)$.

\section{Discussion}

This study shows that polypharmacy with respiratory drugs is common in patients with mild to very severe COPD referred for pulmonary rehabilitation. In addition to the severity of chronic airflow limitation, health status and the number of recent exacerbations are independent predictors of number of respiratory medications used by these patients. A vast majority of patients use long-acting bronchodilators and inhaled corticosteroids and the proportion of COPD patients taking these respiratory medications is comparable in all stages of the disease. Also, the use of inhaled or systemic corticosteroids is not restricted to patients with frequent exacerbations. The results of this study suggest that actual drug use in COPD patients is inconsistent with the current GOLD guidelines and that overprescription of long-acting bronchodilators and both inhaled and systemic corticosteroids is very common in COPD patients with persistent symptoms. Overprescription of respiratory drugs is not only a potential source of unnecessary expense, but is also a risk factor for adverse drug effects and poor adherence.

The overall approach to management of stable COPD is characterized by an increase in pharmacologic treatment depending on both severity of airflow obstruction and the clinical status of the patient. The observed association between number of respiratory drugs used by patients with COPD and GOLD stage is in line with the recommended cumulative introduction of pharmacotherapy. Regarding this approach, the positive association between the number of recent exacerbations and the number of medications could also be anticipated. However, health status was an additional independent predictor of polypharmacy in this study. One possible explanation for this finding is that new pharmaceutical agents are repeatedly added during visits to the outpatient clinic in COPD patients with persistent symptoms and/or limited physical activity. This hypothesis is supported by the fact that poor walking distance was an independent predictor of the number respiratory drugs in this study. By the time that the complete pharmacologic arsenal has been applied and patients nevertheless remain symptomatic, they are referred for pulmonary rehabilitation by the respiratory physicians. ${ }^{27}$ The use of multiple respiratory medications in this study may thus reflect the tertiary care setting of this study, including more complex COPD patients, irrespective of GOLD stage. Nevertheless, pulmonary drug therapy remains inconsistent with the current GOLD guidelines. Furthermore, it should be noted that not more than $22 \%$ of variance in the number of respiratory medications was explained by the presented model. Despite the inclusion of a comprehensive set of objective parameters in the current analysis, other factors probably contribute. The duration of disease, number of consulted physicians, and presence of comorbid conditions are some of these potential contributing factors.

Preserving health status is one of the main objectives of treatment for COPD, and pharmaceutical trials have 
consistently shown positive effects on this outcome. ${ }^{5,6}$ However, in the present study, the worst health status was observed in those patients using the most respiratory drugs, independent of the severity of disease. Although health status in these patients might have been even more impaired with less comprehensive pharmacotherapy, this observation suggests that the effects of respiratory drugs on health status are limited and emphasizes the importance of nonpharmacologic interventions in COPD patients with persistent symptoms, like pulmonary rehabilitation. ${ }^{27}$

Although polypharmacy with respiratory drugs is likely an indicator of poor health status in COPD, a direct negative effect of multiple medication on health status cannot be excluded. Use of multiple medication is associated with poor self-rated health status among all age groups in the general population. ${ }^{28}$ In line with the present study, high daily consumption of respiratory drugs was the only independent correlate of all component scores and of the total SGRQ score in a cross-sectional study including elderly patients with asthma and COPD. ${ }^{29}$

Bronchodilator medications for inhaled therapy are central to the symptomatic management in COPD, and improve lung function, exercise performance, and health status. ${ }^{14}$ Short-acting bronchodilators are recommended for all stages of disease when needed. Contrary to expectations, the majority of GOLD 1 patients and $15 \%-50 \%$ of GOLD 2 to 4 patients did not use any short-acting bronchodilators, despite being referred for pulmonary rehabilitation due to persistent symptoms. This suggests undertreatment with this class of respiratory drugs and inconsistency with the current GOLD guideline. ${ }^{14}$ On the other hand, the present study found a marked predominance of use of long-acting bronchodilators in both mild and more advanced disease. This suggests that long-acting bronchodilators are prescribed as first-line therapy in all symptomatic patients with COPD, irrespective of GOLD stage. Although the international guidelines advise the use of long-acting bronchodilators only in GOLD stages 2 to $4,{ }^{14}$ several pharmaceutical trials indicated additional beneficial effects of long-acting bronchodilators over shortacting bronchodilators on lung function, dyspnea, and health status in patients with severe COPD. ${ }^{30,31}$ Little is known about the effects of long-acting bronchodilators in mild-tomoderate COPD. A recent prespecified subgroup analysis of the Understanding Potential Long-Term Impacts on Function with Tiotropium (UPLIFT) study showed improved outcomes, including lung function and health status, with a long-acting anticholinergic drug compared with placebo. ${ }^{13}$ In addition, long-term long-acting anticholinergic therapy seemed to reduce the rate of decline in postbronchodilator $\mathrm{FEV}_{1}$ in moderate $\mathrm{COPD},{ }^{13}$ suggesting that starting therapy with long-acting anticholinergics is indicated at a more early stage of the disease.

According to the present GOLD guideline, the role of regular treatment with inhaled corticosteroids in the management of COPD is limited to symptomatic patients with severe to very severe disease $\left(\mathrm{FEV}_{1}<50 \%\right.$ predicted) and repeated exacerbations. ${ }^{14}$ In this category of patients, treatment with inhaled corticosteroids reduces the frequency of exacerbations and improves health status. ${ }^{32}$ In the present analyses of actual drug use in clinical practice, the majority of patients with COPD used inhaled corticosteroids, irrespective of the degree of airflow limitation and occurrence of exacerbations. This observation is in line with an earlier study reporting a very high proportion of COPD patients being administered inhaled corticosteroids, conflicting with national guidelines at that time. ${ }^{33}$ Although there still is no clear evidence of the benefit of earlier treatment with inhaled corticosteroids in COPD, a recent randomized placebo-controlled trial in GOLD stage 2 patients showed that long-term inhaled corticosteroid therapy improved airway inflammation, dyspnea and health status. ${ }^{12}$ Furthermore, in contrast with older large COPD trials, ${ }^{34,35}$ this trial suggested that inhaled corticosteroid therapy has the potential to attenuate $\mathrm{FEV}_{1}$ decline in moderate disease.

Short-term courses with systemic corticosteroids are advised in the management of COPD exacerbations but, based on lack of evidence of benefit, chronic treatment should be avoided.${ }^{14}$ Contrary to the GOLD recommendations, a substantial proportion of patients in the current study were taking long-term oral prednisone, especially in the subgroup of patients with frequent exacerbations. In view of the well known toxicity of these drugs, this is an unfavorable observation. Although the current GOLD guideline does not advocate the use of antioxidants, such as $\mathrm{N}$-acetylcysteine, in the treatment of stable COPD,${ }^{14}$ widespread use of this agent in all GOLD stages was reported in the current real-life analyses. Although adverse effects of $\mathrm{N}$-acetylcysteine are limited, ${ }^{36}$ overprescription usually increases the costs of treatment, which is an unwanted consequence considering the high impact of COPD on the health care system. ${ }^{1}$ Finally, a significant proportion of patients in this study used oral theophylline, which is considered an effective bronchodilator in COPD, subordinated to inhaled bronchodilator therapy due to the potential for toxicity. ${ }^{14}$ However, recent studies suggest a future role for combination therapy of low-dose theophylline with inhaled corticosteroids in COPD. ${ }^{37}$ 
The results of the present survey confirm the clinical observations of respiratory prescriptions during day-to-day contact with COPD patients. They indicate that the routine practice of respiratory physicians is only partially consistent with current guidelines. There are several potential causes for the discrepancy between observed respiratory medication use and international guidelines. Following worldwide dissemination of the GOLD guidelines since their introduction nearly a decade ago, it is unlikely that respiratory physicians are not aware of these international recommendations. However, traditional ongoing medical education in the form of printed copies of guidelines or lectures may not be effective in implementation of new or updated guidelines and altering physician performance. ${ }^{38}$ Another reason for nonadherence to the guidelines could be an insufficient clinical response to initial pharmacotherapy in patients with COPD, reflected by persistence of symptoms, reduced exercise capacity, or poor health status. Being confronted with a symptomatic and disabled COPD patient could persuade a respiratory physician to initiate additional or alternative medication inconsistent with the guidelines. In addition, disagreement with the suggested approach and knowledge of data not yet incorporated into the current directives are possible reasons for not adhering to guidelines. New insights in the effects of early treatment with long-acting bronchodilators, ${ }^{13}$ inhaled corticosteroids, ${ }^{12}$ or theophylline ${ }^{37}$ are some examples of the recent developments in the field of pharmacologic management of COPD, that require subsequent analyses before being integrated in future international guidelines.

In summary, this study reported discrepancies between international guidelines for pharmacologic management of COPD and actual prescription rates in patients with mild to very severe COPD referred for pulmonary rehabilitation. These symptomatic patients use multiple respiratory medications, and actual respiratory drug use is largely independent of the severity of chronic airflow limitation and the rate of exacerbations. However, health status is an independent predictor of polypharmacy in these patients. In consideration of the existing GOLD guideline, long-acting bronchodilators and both inhaled as well as systemic corticosteroids for maintenance therapy are overprescribed in patients with mild to moderate COPD. In view of the already vast economic impact of COPD on the health care system, overprescription and polypharmacy should be avoided, and respiratory physicians should be encouraged to adhere to evidence-based guidelines for COPD management until new pharmacologic strategies are established.

\section{Acknowledgments}

This work was published on behalf of the CIRO+ network, which consists of the CIRO+, Center of Expertise for Chronic Organ Failure, Horn; Maastricht University Medical Center, Maastricht; St Jans Gasthuis, Weert; Maxima Medical Center, Veldhoven; St Anna Hospital, Geldrop; Laurentius Hospital, Roermond; and Elkerliek Hospital, Helmond, The Netherlands.

\section{Disclosure}

The authors report no conflicts of interest in this work.

\section{References}

1. Wouters EF. Economic analysis of the Confronting COPD survey: an overview of results. Respir Med. 2003;97 Suppl C:S3-S14.

2. Murray CJ, Lopez AD. Alternative projections of mortality and disability by cause 1990-2020: Global Burden of Disease Study. Lancet. 1997;349(9064):1498-1504.

3. Sestini P, Renzoni E, Robinson S, Poole P, Ram FS. Short-acting beta 2 agonists for stable chronic obstructive pulmonary disease. Cochrane Database Syst Rev. 2002;4:CD001495.

4. Lung Health Study Research Group. Effect of inhaled triamcinolone on the decline in pulmonary function in chronic obstructive pulmonary disease. N Engl J Med. 2000;343(26):1902-1909.

5. Tashkin DP, Celli B, Senn S, et al. A 4-year trial of tiotropium in chronic obstructive pulmonary disease. N Engl J Med. 2008;359(15): 1543-1554.

6. Calverley PM, Anderson JA, Celli B, et al. Salmeterol and fluticasone propionate and survival in chronic obstructive pulmonary disease. N Engl J Med. 2007;356(8):775-789.

7. O'Donnell DE, Fluge T, Gerken F, et al. Effects of tiotropium on lung hyperinflation, dyspnoea and exercise tolerance in COPD. Eur RespirJ. 2004;23(6):832-840.

8. Liesker JJ, Wijkstra PJ, Ten Hacken NH, Koeter GH, Postma DS, Kerstjens HA. A systematic review of the effects of bronchodilators on exercise capacity in patients with COPD. Chest. 2002;121(2): 597-608.

9. Paggiaro PL, Dahle R, Bakran I, Frith L, Hollingworth K, Efthimiou J. Multicentre randomised placebo-controlled trial of inhaled fluticasone propionate in patients with chronic obstructive pulmonary disease. International COPD Study Group. Lancet. 1998;351(9105):773-780.

10. Celli B, Decramer M, Kesten S, Liu D, Mehra S, Tashkin DP. Mortality in the 4-year trial of tiotropium (UPLIFT) in patients with chronic obstructive pulmonary disease. Am J Respir Crit Care Med. 2009; 180(10):948-955.

11. Celli BR, Thomas NE, Anderson JA, et al. Effect of pharmacotherapy on rate of decline of lung function in chronic obstructive pulmonary disease: results from the TORCH study. Am J Respir Crit Care Med. 2008;178(4):332-338.

12. Lapperre TS, Snoeck-Stroband JB, Gosman MM, et al. Effect of fluticasone with and without salmeterol on pulmonary outcomes in chronic obstructive pulmonary disease: a randomized trial. Ann Intern Med. 2009;151(8):517-527.

13. Decramer M, Celli B, Kesten S, Lystig T, Mehra S, Tashkin DP. Effect of tiotropium on outcomes in patients with moderate chronic obstructive pulmonary disease (UPLIFT): a prespecified subgroup analysis of a randomised controlled trial. Lancet. 2009;374(9696):1171-1178.

14. Global Initiative for Obstructive Lung Disease. Global strategy for the diagnosis, management and prevention of chronic obstructive pulmonary disease (updated 2010). 2010;1-117. Available from: http://www.goldcopd.org/guidelines-global-strategy-for-diagnosismanagement.html. Accessed September 16, 2011. 
15. Vathenen AS, Britton JR, Ebden P, Cookson JB, Wharrad HJ, Tattersfield AE. High-dose inhaled albuterol in severe chronic airflow limitation. Am Rev Respir Dis. 1988;138(4):850-855.

16. Bourbeau J, Bartlett SJ. Patient adherence in COPD. Thorax. 2008;63(9): 831-838.

17. Gokce Kutsal Y, Barak A, Atalay A, et al. Polypharmacy in the elderly: a multicenter study. J Am Med Dir Assoc. 2009;10(7):486-490.

18. Annegarn J, Meijer K, Passos VL, et al. Problematic activities of daily life are weakly associated with clinical characteristics in COPD. J Am Med Dir Assoc. February 15, 2011. [Epub ahead of print.]

19. Wedzicha JA, Seemungal TA. COPD exacerbations: defining their cause and prevention. Lancet. 2007;370(9589):786-796.

20. Spruit MA, Vanderhoven-Augustin I, Janssen PP, Wouters EF. Integration of pulmonary rehabilitation in COPD. Lancet. 2008;371(9606): $12-13$.

21. Quanjer PH, Tammeling GJ, Cotes JE, Pedersen OF, Peslin R, Yernault JC. Lung volumes and forced ventilatory flows. Report Working Party Standardization of Lung Function Tests, European Community for Steel and Coal. Official Statement of the European Respiratory Society. Eur Respir J Suppl. 1993;16:5-40.

22. Schols AM, Wouters EF, Soeters PB, Westerterp KR. Body composition by bioelectrical-impedance analysis compared with deuterium dilution and skinfold anthropometry in patients with chronic obstructive pulmonary disease. Am J Clin Nutr. 1991;53(2):421-424.

23. Hernandes NA, Wouters EF, Meijer K, Annegarn J, Pitta F, Spruit MA Reproducibility of 6-minute walking test in patients with COPD. Eur Respir J. 2011;38(2):261-267.

24. Troosters T, Gosselink R, Decramer M. Six minute walking distance in healthy elderly subjects. Eur Respir J. 1999;14(2):270-274.

25. Bestall JC, Paul EA, Garrod R, Garnham R, Jones PW, Wedzicha JA. Usefulness of the Medical Research Council (MRC) dyspnoea scale as a measure of disability in patients with chronic obstructive pulmonary disease. Thorax. 1999;54(7):581-586.

26. Jones PW, Quirk FH, Baveystock CM, Littlejohns P. A self-complete measure of health status for chronic airflow limitation. The St George's Respiratory Questionnaire. Am Rev Respir Dis. 1992;145(6): 1321-1327.

27. Nici L, Donner C, Wouters E, et al. American Thoracic Society/ European Respiratory Society statement on pulmonary rehabilitation. Am J Respir Crit Care Med. 2006;173(12):1390-1413.
28. Moen J, Antonov K, Larsson CA, et al. Factors associated with multiple medication use in different age groups. Ann Pharmacother. 2009;43(12):1978-1985.

29. Incalzi RA, Bellia V, Catalano F, et al. Evaluation of health outcomes in elderly patients with asthma and COPD using disease-specific and generic instruments: the Salute Respiratoria nell'Anziano (Sa.R.A.) Study. Chest. 2001;120(3):734-742.

30. Vincken W, van Noord JA, Greefhorst AP, et al. Improved health outcomes in patients with COPD during 1 yr's treatment with tiotropium. Eur Respir J. 2002;19(2):209-216.

31. Mahler DA, Donohue JF, Barbee RA, et al. Efficacy of salmeterol xinafoate in the treatment of COPD. Chest. 1999;115(4):957-965.

32. Spencer S, Calverley PM, Burge PS, Jones PW. Impact of preventing exacerbations on deterioration of health status in COPD. Eur Respir J. 2004;23(5):698-702.

33. Roche N, Lepage T, Bourcereau J, Terrioux P. Guidelines versus clinical practice in the treatment of chronic obstructive pulmonary disease. Eur Respir J. 2001;18(6):903-908.

34. Burge PS, Calverley PM, Jones PW, Spencer S, Anderson JA, Maslen TK. Randomised, double blind, placebo controlled study of fluticasone propionate in patients with moderate to severe chronic obstructive pulmonary disease: the ISOLDE trial. BMJ. 2000;320(7245): 1297-1303.

35. Vestbo J, Sorensen T, Lange P, Brix A, Torre P, Viskum K. Long-term effect of inhaled budesonide in mild and moderate chronic obstructive pulmonary disease: a randomised controlled trial. Lancet. 1999; 353(9167):1819-1823.

36. Decramer M, Rutten-van Molken M, Dekhuijzen PN, et al. Effects of N-acetylcysteine on outcomes in chronic obstructive pulmonary disease (Bronchitis Randomized on NAC Cost-Utility Study, BRONCUS): a randomised placebo-controlled trial. Lancet. 2005; 365(9470):1552-1560.

37. Ford PA, Durham AL, Russell RE, Gordon F, Adcock IM, Barnes PJ. Treatment effects of low dose theophylline combined with an inhaled corticosteroid in COPD. Chest. 2010;137(6):1338-1344.

38. Davis D, O'Brien MA, Freemantle N, Wolf FM, Mazmanian P, Taylor-Vaisey A. Impact of formal continuing medical education: do conferences, workshops, rounds, and other traditional continuing education activities change physician behavior or health care outcomes? JAMA. 1999;282(9):867-874.
International Journal of COPD

\section{Publish your work in this journal}

The International Journal of COPD is an international, peer-reviewed journal of therapeutics and pharmacology focusing on concise rapid reporting of clinical studies and reviews in COPD. Special focus is given to the pathophysiological processes underlying the disease, intervention programs, patient focused education, and self management protocols.

\section{Dovepress}

This journal is indexed on PubMed Central, MedLine and CAS. The manuscript management system is completely online and includes a very quick and fair peer-review system, which is all easy to use. Visit http://www.dovepress.com/testimonials.php to read real quotes from published authors. 